\title{
REPORT
}

\section{Infants' memory for musical performances}

\section{Anna Volkova, Sandra E. Trehub and E. Glenn Schellenberg}

\author{
Department of Psychology, University of Toronto, Canada
}

\begin{abstract}
We evaluated 6- and 7-month-olds' preference and memory for expressive recordings of sung lullabies. In Experiment 1, both age groups preferred lower-pitched to higher-pitched renditions of unfamiliar lullabies. In Experiment 2, infants were tested after 2 weeks of daily exposure to a lullaby at one pitch level. Seven-month-olds listened significantly longer to the lullaby at a novel pitch level than at the original pitch level. Six-month-olds showed no preference but their low-pitch preference was eliminated. We conclude that infants' memory for musical performances is enhanced by the ecological validity of the materials. Moreover, infants' pitch preferences are influenced by their previous exposure and by the nature of the music.
\end{abstract}

\section{Introduction}

Recollections of Martin Luther King's 'I have a dream' speech evoke King's passionate delivery as well as his ideas. Similarly, the memorable message in John F. Kennedy's inaugural address ('... ask not what your country can do for you; ask what you can do for your country') was enhanced by his vigorous voice and distinctive dialect. Individual performing styles figure even more prominently in music. Louis Armstrong's unique voice quality and phrasing transformed simple tunes and lyrics into riveting performances that transcended the musical materials. Our memory for specific songs is often linked to singular performances like John Lennon's 'Imagine' or Bob Dylan's 'Like a Rolling Stone'. The vocal features that distinguish one artist's performance of the same material from another's (or the same artist's performances on different occasions) include pitch level, voice quality, tempo, and expressive variations in intensity, pitch, and timing.

Our encoding and retention of performance features enable us to identify recordings of songs from miniscule fragments $(100-200 \mathrm{~ms})$, well before the tune or voice can be identified (Schellenberg, Iverson \& McKinnon, 1999). Fine-grained mental representations also enable us to distinguish musical excerpts that accompany familiar television programs from versions that are pitch-shifted by one or two semitones (Schellenberg \& Trehub, 2003). Most individuals cannot remember performance features in isolation, nor can they accurately reproduce the performances of others. Nevertheless, they recognize the constellation of cues in an authentic performance.

The nature of vocal performances may be at least as important for infants as for adults. For example, what mothers say is far less important than how they say it (Fernald, 1991; Singh, Morgan \& Best, 2002; Trainor, Austin \& Desjardins, 2000). Similarly, how mothers sing to infants is more important than what they sing (Masataka, 1999; Trainor, 1996). In fact, expressive features of sung performances - loving voice quality, in particular - predict infants' preferences (Trainor, 1996). Despite the impact of maternal singing on infant attention (Nakata \& Trehub, 2004) and arousal (Shenfield, Trehub \& Nakata, 2003), studies of infants' long-term memory for music have focused on non-vocal materials. In the present study, we focused on infants' memory for vocal performances.

The available literature is instructive in what it reveals about infants' memory for music. Saffran, Loman and Robertson (2000) exposed 7-month-old infants to portions of two Mozart piano sonatas for 2 weeks. After a retention interval of 2 weeks, they evaluated infants' preference for 20 -s excerpts from the familiar sonatas and from two other Mozart sonatas performed by the same pianist (Mitsuko Uchida). Infants listened longer to the novel excerpts, which confirmed their long-term memory for the musical material heard at home. Because the familiar and novel music differed in several respects, including pitch level or key, the factors that contributed to infants' recognition remain unclear. 
Trainor, Wu and Tsang (2004) exposed 6-month-old infants to simpler musical materials. Instead of commercial recordings (as in Saffran et al., 2000), infants heard synthesized piano or harp renditions of a folk tune every day for a week. After a 1-day retention interval, infants listened longer to a novel folk tune than to the familiar tune, which confirmed their memory for the tune heard previously. In further experiments with the same exposure and retention interval, infants showed no preferences when tested with familiar and novel tunes both presented at a novel tempo (faster or slower) or timbre (e.g. piano to harp). The authors interpreted this null finding as evidence of infants' long-term memory for tempo and timbre. Although salient changes from encoding to retrieval contexts (i.e. tempo or timbre changes) may have been responsible for infants' recognition failure, this does not imply that infants remembered the original tempo or timbre. Rather, infants' mental representation of the tune may simply be fragile or inflexible (Munakata, 2001). Peretz, Gaudreau and Bonnel (1998) found that timbre differences between encoding and retrieval contexts impaired adults' recognition of musical pieces, but they did not claim that adults remembered the original timbre. Similarly, word recognition failures resulting from changes in talker or vocal affect between familiarization and test (Houston \& Jusczyk, 2000, 2003; Singh, Morgan \& White, 2004) may raise questions about infants' memory for talker or affect cues, but they do not resolve these questions. More compelling evidence of infants' memory for the timbre or tempo of musical performances would be indicated by preferential listening for the original tune with novel timbre or tempo than with all performance features intact - a condition that was not tested by Trainor et al. (2004).

In a further study, Plantinga and Trainor (2005) familiarized 6-month-olds with a piano rendition of one of the same folk tunes for 7 days, then tested them a day later on the familiar and novel tunes, both presented at a novel pitch level (6 or 7 semitones higher or lower than the original). Infants listened longer to the novel tune, which confirmed their memory for the familiar tune despite the altered pitch level. When infants were given a choice between the familiar tune at the original pitch level or at a novel pitch level, they showed no preference. The findings indicate the salience of relative pitch cues for these stimuli, but other research indicates that adults' as well as infants' memory for absolute and relative pitch cues varies as a function of stimulus and task (Saffran, Reeck, Neibuhr \& Wilson, 2005; Schellenberg \& Trehub, 2003).

The aforementioned studies of infants' long-term memory for music reveal that after relatively limited exposure (1-2 weeks), infants remember simple monophonic melodies or complex musical pieces that they hear at home. They also recognize simple tunes heard at home when they are presented at a novel pitch level (Plantinga \& Trainor, 2005), which is consistent with their short-term memory for transposed melodies (Trehub, Thorpe \& Morrongiello, 1987). Although infants encode performance-specific features of music when tested immediately after exposure (Palmer, Jungers \& Jusczyk, 2001), it is unclear whether they retain expressive performance cues over longer periods. Obviously, synthesized, inexpressive musical stimuli, such as those used by Trainor et al. (2004) and Plantinga and Trainor (2005), reduce the salience of performance cues.

There are several reasons why some aspects of expressive musical performances, especially pitch level, should be important to infants. As noted, infants prefer infantdirected (ID) to non-ID singing, even in the newborn period (Masataka, 1999). Mothers' ID and non-ID performances of the same song differ in expressive quality, which includes elevated pitch level for the ID performance (Bergeson \& Trehub, 1999; Trainor, 1996; Trainor, Clark, Huntley \& Adams, 1997; Trehub, Unyk, Kamenetsky, Hill, Trainor, Henderson \& Saraza, 1997). Elevated pitch also distinguishes mothers' expressive performances of the same song for different audiences (infant or preschooler; Bergeson \& Trehub, 1999), and it is a prominent feature of ID speech (Fernald, 1991). In the single study that examined infants' preference for songs as a function of pitch level, infants preferred the higher-pitched renditions (Trainor \& Zacharias, 1998). The generalizability of this finding is questionable, however, because the performers did not use an ID singing style and, at times, they sang substantially above or below their usual pitch level.

The purpose of the present investigation was to determine whether infants remember familiar expressive performances, as reflected in their ability to differentiate those performances from others that differ primarily in pitch level. Accordingly, 6- and 7-month-old infants listened to vocal renditions of foreign lullabies every day for 2 weeks, after which they were tested on the original rendition and a rendition sung four semitones higher or lower than the original. Because of the importance of expressive performance cues for adult listeners and the importance of pitch level in mothers' spoken and sung interactions with infants (Fernald, 1991; Trehub \& Trainor, 1998), we expected infants to remember the original performances. Their memory would be indicated by a listening preference for the rendition performed at a novel pitch level.

It was necessary to determine first whether infants with no prior exposure to these performances would 
exhibit any preferences. Although North American mothers tend to elevate their pitch level when singing to infants (Bergeson \& Trehub, 1999; Trainor, 1996; Trehub et al., 1997), this modification may be more common for lively play songs than for soothing lullabies (Trehub \& Trainor, 1998). Elevated pitch may enhance the expressiveness of play songs but not of lullabies. If infants' preferences for singing are based on its expressiveness, as in speech (Singh et al., 2002), then infants may prefer higher-pitched versions of play songs but lower-pitched versions of lullabies. In any case, we predicted that the preferences of infants with long-term exposure to lullaby performances would differ from those without such exposure.

\section{Experiment 1}

We sought to evaluate infants' natural preference for lullaby performances as a function of their pitch level. Accordingly, we assessed 6- and 7-month-old infants' preference for higher- and lower-pitched versions of unfamiliar lullabies by means of the headturn-preference procedure (Hannon \& Trehub, 2005; Trainor et al., 2004). We selected traditional lullabies from Russia, Germany, and Spain, and generated very soothing vocal performances modeled on traditional renditions sung by caregivers in those cultures. There were two recorded versions of each lullaby - one sung in a lower pitch register, the other in a higher register.

\section{Method}

\section{Participants}

The participants were 197 -month-olds ( $M=7.8$ months) and 17 6-month-olds ( $M=6.6$ months) who were healthy, born at term, and had no family history of hearing problems.

\section{Apparatus}

Participants were tested in a quiet, dimly lit room. The infant was seated on a parent's lap, facing two 17-in monitors (Sony) $140 \mathrm{~cm}$ apart, each 45 degrees from the infant at a distance of $93 \mathrm{~cm}$. Trial presentation and response recording were controlled by a Macintosh G4 computer with customized software. The musical stimuli were presented from a hidden, centrally located loudspeaker (Altec Lansing AC 522). The experimenter monitored the infant through a hole in a partition that concealed the computer and experimenter. Parent and experimenter listened to music over headphones, which prevented them from hearing the musical materials presented to infants.

\section{Stimuli}

The stimuli were four traditional folk lullabies - two German, one Spanish, and one Russian - sung in a traditional, informal manner, without accompaniment. A trained female singer produced two expressive, soothing renditions of each lullaby with the original, foreign lyrics. She matched the tempo and expressive qualities as closely as possible in her two renditions of each song, which differed in pitch level by four semitones. Samples of the stimuli are available at http:// www.utm.utoronto.ca/ w3trehub/is/research.htm. The higherand lower-pitched versions of each song were in the soprano and alto ranges, respectively. Three lullabies were in the major mode and one was in the minor mode. Each infant, who was randomly assigned to one lullaby, was tested on the two renditions of that lullaby. The musical stimuli were prepared as QuickTime movies accompanied by an animated display (i.e. a multicolored, revolving globe) that was identical across lullabies. Each lullaby performance was presented along with the animated display on one monitor. For any infant, the same (e.g. high-pitched) version was always accompanied by the animated display on one side (e.g. right), and the other (e.g. lower-pitched) version was always accompanied by the same visual display on the other side (e.g. left). Half of the infants received the highpitched version first, and half received the low-pitched version first. The high- and low-pitched versions were counterbalanced with the left and right monitors.

\section{Procedure}

The hidden tester recorded all instances of infant looking toward and away from either monitor by pressing different keys on a keypad. As soon as the infant seemed quiet and comfortable, a flashing red screen on one monitor attracted the infant's attention to that monitor. When the infant looked at the monitor, the presentation of one lullaby rendition began, along with the animated display. The presentation of audio-visual materials continued until the infant looked away for $2 \mathrm{~s}$, or $30 \mathrm{~s}$ had elapsed. After a 3-s silent period, a flashing red screen on the other monitor attracted the infant's attention to the opposite side. When the infant looked at that monitor, the contrasting lullaby rendition was presented, along with the dynamic visual display that had appeared on the other side. As before, stimulus presentation continued until the infant looked away for $2 \mathrm{~s}$, or $30 \mathrm{~s}$ had elapsed. Trials of the high- and low-pitched renditions of the lullaby alternated until the infant completed a total of 10 trials, five with each rendition. 


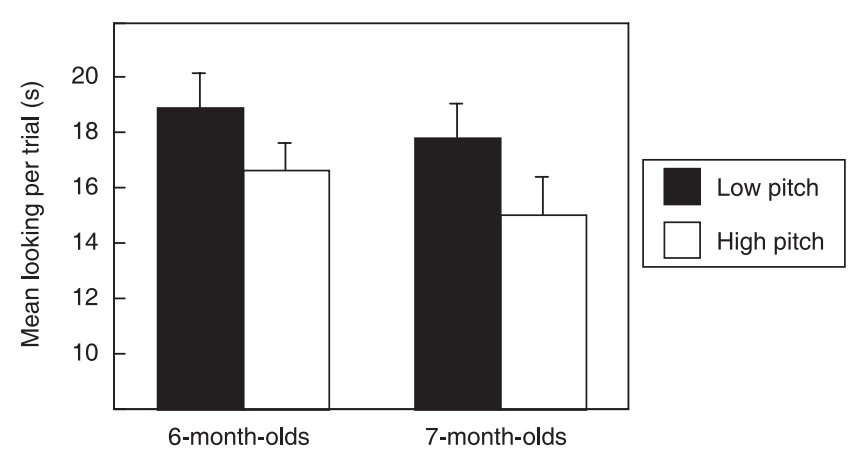

Figure 1 Average looking times for infants in Experiment 1 (no previous exposure) as a function of age and pitch level. Error bars are standard errors.

\section{Results}

Because infants tended to look considerably longer on the initial trial than on subsequent trials, looking times on the first two trials (i.e. first exposure to each lullaby rendition) were excluded from consideration. The outcome measures were average looking times per trial for each infant, calculated separately for high-pitched and low-pitched versions of the lullaby (see Figure 1). The data were analyzed with a two-way mixed-design analysis of variance (ANOVA), with pitch of the lullaby as a within-subjects variable and age group as a betweensubjects variable. There was no main effect of age group and no interaction between age group and pitch level, $F$ s $<1$, but the main effect of pitch level was significant, $F(1,34)=9.43, p=.004$. As can be seen in Figure 1, there was a robust preference for the low-pitched versions $(M=18.33 \mathrm{~s}, \mathrm{SD}=5.33 \mathrm{~s})$ over the high-pitched versions $(M=15.80 \mathrm{~s}, \mathrm{SD}=5.08 \mathrm{~s})$. Thus, contrary to the reported preference for higher-pitched renditions of songs (Trainor \& Zacharias, 1998), 6- and 7-month-old infants in the present study preferred the lower-pitched renditions of expressively sung lullabies.

\section{Experiment 2}

We examined infants' memory for expressive performances of vocal music by exposing 6- and 7-month-olds to two lullabies every day for 2 weeks. One lullaby was performed at a relatively low pitch level and the other at a higher pitch level. Subsequently, infants were tested on their preference for high- and low-pitched versions of one of the lullabies heard at home. We predicted that infants would remember the lullaby version heard at home, leading to longer listening times for the novel pitch level. Memory for the familiar performance would also be indicated by different listening preferences for infants exposed to the lullabies (i.e. those in the present experiment) and those without such exposure (i.e. infants in Experiment 1).

\section{Method \\ Participants}

The participants were 216 -month-olds ( $M=6.7$ months at the time of preference testing) and 237 -month-olds ( $M=7.8$ months at the time of testing). All infants were healthy, born at term, and had no family history of hearing problems. Additional infants were excluded because of fussiness $(n=7)$ and equipment problems $(n=1)$ during the preference test.

\section{Apparatus}

The apparatus was the same as in Experiment 1.

Stimuli

The stimuli were the same as those in Experiment 1 . Compact disks $(n=8)$ featuring two lullabies from different countries were prepared for each infant. One lullaby on the disk appeared in its high-pitched rendition, the other in its low-pitched rendition. For each lullaby pair, the high-pitched version appeared first half of the time. The two lullaby performances repeated in alternating order, five times each, with 2-s pauses between renditions, for a total playing time of approximately $6 \mathrm{~min}$.

\section{Procedure}

Parents received their $\mathrm{CD}$ in the mail, along with instructions to play it twice daily for 14 days during periods when their infant was awake and alert. Parents were instructed to maintain the infant's usual routine without drawing attention to the music. On the fifteenth day, infants visited the laboratory to participate in a preference test like that described in Experiment 1. At that time, infants were presented with two renditions of the first lullaby that had appeared on their $\mathrm{CD}$, one at the original pitch level and one four semitones higher or lower (counterbalanced order).

\section{Results}

As in Experiment 1, we discarded looking times for the first two trials before calculating average looking times for the high- and low-pitched test lullabies (see Figure 2). The data were analyzed with a three-way mixed-design 


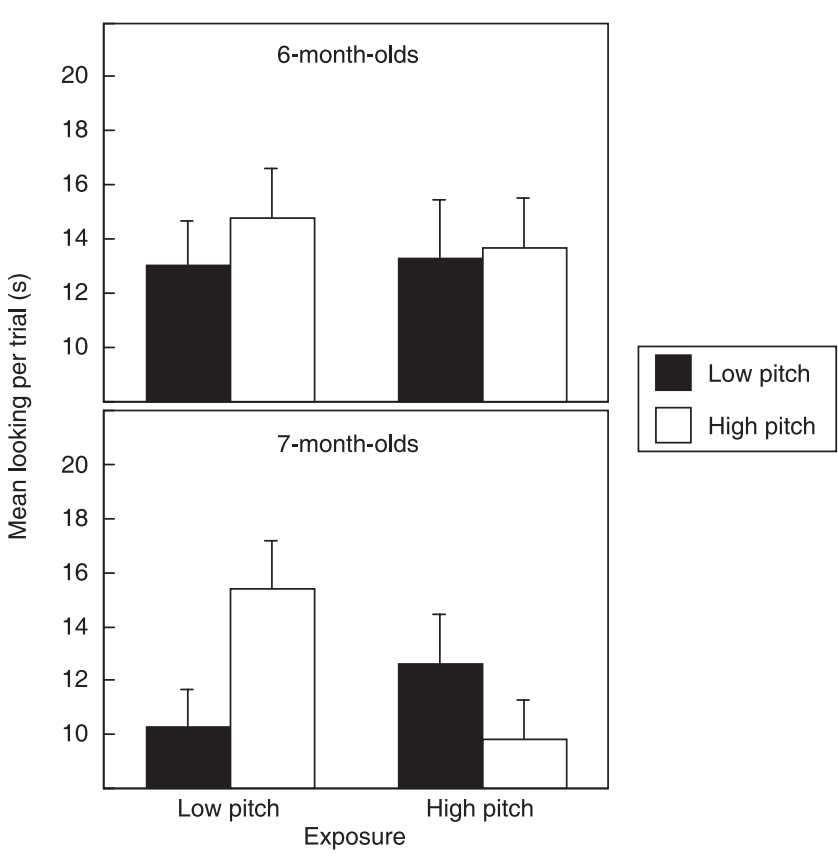

Figure 2 Average looking times in Experiment 2 (2 weeks of daily exposure) for 6-month-olds (upper) and 7-month-olds (lower) as a function of pitch of exposure and pitch at test time. Error bars are standard errors.

ANOVA, with age group (6 or 7 months) and homeexposure (low or high pitch) as between-subjects variables, and pitch of the test lullaby (low or high) as a withinsubjects variable. Preference for the novel pitch level was indicated by a highly significant two-way interaction between home-exposure pitch and test pitch, $F(1,40)=$ $12.06, p=.001$. Infants looked significantly longer to hear the familiar lullaby performed at a novel pitch level $(M=13.82 \mathrm{~s}, \mathrm{SD}=6.23 \mathrm{~s})$ than at the familiar pitch level $(M=11.58 \mathrm{~s}, \mathrm{SD}=5.36 \mathrm{~s})$. Nonetheless, a significant three-way interaction, $F(1,40)=5.94, p=.019$, indicated that the preference for novel pitch varied with age.

Accordingly, we analyzed the two age groups separately with two-way (pitch at exposure $\times$ pitch at test) ANOVAs. For 7-month-olds, the two-way interaction was highly significant, $F(1,21)=19.92, p<.001$, revealing a robust novelty preference (Figure 2 , lower). On average, looking time per trial was $13.59 \mathrm{~s}(\mathrm{SD}=6.36 \mathrm{~s})$ for the novel pitch level but only $9.99 \mathrm{~s}(\mathrm{SD}=4.86 \mathrm{~s})$ for the familiar pitch level. For 6-month-olds, however, there was no main effect of pitch of exposure, no main effect of pitch at test, and no interaction (Figure 2, upper). Thus, for the younger group, home exposure to the lullaby eliminated the pre-existing low-pitch preference that was evident in Experiment 1. This observation was evaluated statistically by comparing 6-month-olds from Experiment 1 (no previous exposure) to 6-month-olds from Experiment 2 (2 weeks of exposure) with a two-way (previous exposure $\times$ pitch at test) mixed-design ANOVA. A reliable two-way interaction, $F(1,36)=5.01, p=.032$, confirmed that pitch preferences varied as a function of exposure. The analysis also revealed a main effect of exposure, $F(1,36)=6.80, p=.013$, or a 'general novelty preference' for 6-month-olds who had never heard the lullabies previously. Specifically, looking times per trial were over $4 \mathrm{~s}$ longer for infants with no prior exposure to the lullabies $(M=17.78 \mathrm{~s}, \mathrm{SD}=4.59 \mathrm{~s})$ than for infants with 2 weeks of at-home exposure $(M=13.70 \mathrm{~s}$, $\mathrm{SD}=5.83 \mathrm{~s}$ ).

\section{Discussion}

In Experiment 1, 6- and 7-month-old infants with no previous exposure to the test lullabies showed a significant preference for the lower-pitched renditions. Although this finding is at odds with the high-pitch preference reported previously for sung performances (Trainor \& Zacharias, 1998), it is not surprising that the nature of the music affects infant preferences (Saffran et al., 2005). The low-pitched versions of the lullabies may have been more compatible with other soothing aspects of these performances, such as their very slow tempo and smooth transitions between notes (i.e. legato articulation). For speech, the presumption is that high pitch underlies infants' preference for ID over adult-directed (AD) versions (Fernald, 1991; Papoušek, 1992). This preference is typically assessed with playful ID speech, however, which also differs in speaking rate, repetitiveness, rhythm, tone of voice, and verbal content (Cooper \& Aslin, 1990; Fernald, 1985; Werker \& McLeod, 1989). When vocal affect and register (ID/AD) are manipulated independently, infants' preference for positive vocal affect overrides their preference for other aspects of ID speech (Kitamura \& Burnham, 1998; Singh et al., 2004). Interestingly, the features of loving or comforting ID speech - low pitch, slow tempo, and downward pitch contours (Fernald, 1989; Trainor et al., 2000) - also characterize lullabies (Trainor \& Trehub, 1998; Unyk, Trehub, Trainor \& Schellenberg, 1992), in contrast to ID expressions of surprise, approval, or attention-bid, which feature higher pitch, broader pitch range, and faster tempo (Fernald, 1989; Trainor et al., 2000).

An alternative interpretation of the low pitch preference in Experiment 1 implicates novelty. If infants were accustomed to higher-pitched singing because of mothers' inclination to sing play songs rather than lullabies (Trehub et al., 1997), then our low-pitched lullabies may 
have evoked interest because of their novel vocal range. It is worth noting that the magnitude of infants' reported preference for high-pitched singing (Trainor \& Zacharias, 1998) was considerably greater for performances above the singers' usual vocal range (Experiment 1) than for those within their range (Experiment 2). In line with these suggested consequences of novelty, infants in the present study with no prior exposure to the test lullabies (Experiment 1) had significantly longer looking times than those with 2 weeks of exposure (Experiment 2).

Of principal interest in the present study was infants' memory for expressive performances of sung lullabies. The findings were unambiguous for 7-month-olds, whose memory for familiar performance features was reflected in their preference for the familiar lullaby sung at a novel pitch level. No such preference was evident for 6-montholds. Nevertheless, 6-month-olds with prior exposure to lullaby performances responded differently than 6month-olds with no prior exposure, the latter exhibiting greater overall looking times and a low-pitch preference. Memory for lullaby performances may improve during infancy, in line with graded mental representations (Munakata, 2001) that become more robust and detailed over the course of development. For both age groups, exposure to the lullabies at home influenced looking times in the laboratory, providing unequivocal evidence of their memory for expressively sung performances.

In contrast to the findings of Plantinga and Trainor (2005), infants in the present study responded differentially to musical performances as a function of the familiarity or novelty of their pitch level. We suggest that these divergent findings stem from dramatically different musical materials - synthesized, inexpressive instrumental performances in Plantinga and Trainor (2005) and highly expressive vocal performances in the present study. Undoubtedly, the expressive qualities and vocal cues in the lullaby performances contributed to mean looking times that were more than double those of Plantinga and Trainor (2005). Long looking times in Trainor and Zacharias (1998) also attest to the impact of sung performances. Procedural differences, including greater exposure ( 2 weeks in the present study vs. 1 week in Plantinga \& Trainor) could also account for some of the differences in looking times across laboratories.

With respect to ID speech, Trainor et al. (2000) noted 'the widespread expression of emotion to infants in comparison to the more inhibited expression of emotion in typical adult interactions' (p. 194). These differences in emotional intention and intensity have profound acoustic consequences, which, in turn, have profound behavioral consequences for infant listeners. In our view, differences between the expressively sung music of the present study and the synthesized music of previous studies greatly exceed the differences between ID and AD speech.

Aside from their impact on infant preferences and looking times, expressive cues are likely to enhance infants' learning and retention of information from musical materials, as they do for spoken materials. For example, 7-month-olds more readily extract statistical regularities from syllable sequences with ID rather than AD prosody (Thiessen, Hill \& Saffran, 2005), 4-montholds more readily link faces with typical ID speech than with ID speech from depressed mothers (Kaplan, Bachorowski, Smoski \& Hudenko, 2002), and 1-montholds differentiate mothers' from strangers' speech for normally intonated but not for monotone utterances (Mehler, Bertoncini, Barriere \& Jassik-Gerschenfeld, 1978). The facilitative consequences of expressive vocal cues may be mediated, in part, by enhanced mood, much like the mood-mediated effects of music on adults' and children's performance on a variety of tasks (Schellenberg \& Hallam, 2006; Schellenberg, Nakata, Hunter \& Tamoto, 2007; Thompson, Schellenberg \& Husain, 2001).

Because our stimuli were natural and expressive, they incorporated performance nuances other than pitch level. In fact, changes in pitch level are never entirely independent of other changes. Indeed, the musical term, tessitura, denotes changes in the sound quality of a musical instrument (e.g. piano) that arise from simply moving up and down in pitch level. This issue has no bearing on our principal claim, which is that 6- and 7-month-olds remember expressive performances of lullabies. Infants' attention to and memory for the dynamic cluster of cues in expressive vocal performances may underlie their recognition of voices (DeCasper \& Fifer, 1980; Mehler et al., 1978) and signal their attunement to the expressive intentions of speakers and singers.

\section{Acknowledgement}

Funded by the Social Sciences and Engineering Research Council of Canada.

\section{References}

Bergeson, T.R., \& Trehub, S.E. (1999). Mothers' singing to infants and preschool children. Infant Behavior and Development, 22, 51-64.

Cooper, R.P., \& Aslin, R.N. (1990). Preference for infantdirected speech in the first month after birth. Child Development, 61, 1584-1595.

DeCasper, A.J., \& Fifer, W. (1980). Of human bonding: newborns prefer their mothers' voices. Science, 208, 11741176. 
Fernald, A. (1985). Four-month-old infants prefer to listen to motherese. Infant Behavior and Development, 8, 181-195.

Fernald, A. (1989). Intonation and communicative intent in mothers' speech to infants: is the melody the message? Child Development, 60, 1497-1510.

Fernald, A. (1991). Prosody in speech to children: prelinguistic and linguistic functions. Annals of Child Development, 8, 4380.

Hannon, E.E., \& Trehub, S.E. (2005). Metrical categories in infancy and adulthood. Psychological Science, 16, 48-55.

Houston, D.M., \& Jusczyk, P.W. (2000). The role of talkerspecific information in word segmentation by infants. Journal of Experimental Psychology: Human Perception and Performance, 26, 1570-1582.

Houston, D.M., \& Jusczyk, P.W. (2003). Infants' long-term memory for the sound patterns of words and voices. Journal of Experimental Psychology: Human Perception and Performance, 29, 1143-1154.

Kaplan, P.S., Bachorowski, J., Smoski, M.J., \& Hudenko, W.J. (2002). Infants of depressed mothers, although competent learners, fail to learn in response to their own mothers' infant-directed speech. Psychological Science, 13, 268-271.

Kitamura, C., \& Burnham, D. (1998). The infant's response to maternal vocal affect. In C. Rovee-Collier, L. Lipsitt \& H. Hayne (Eds.), Advances in infancy research (Vol. 12, pp. 221236). Stamford, CT: Ablex.

Masataka, N. (1999). Preference for infant-directed singing in 2-day old hearing infants of deaf parents. Developmental Psychology, 35, 1001-1005.

Mehler, J., Bertoncini, J., Barriere, M., \& Jassik-Gerschenfeld, D. (1978). Infant recognition of mother's voice. Perception, 7, 491-497.

Munakata, Y. (2001). Graded representations in behavioral dissociations. Trends in Cognitive Sciences, 5, 309-315.

Nakata, T., \& Trehub, S.E. (2004). Infants' responsiveness to maternal speech and singing. Infant Behavior and Development, 27, 455-464.

Palmer, C., Jungers, M.K., \& Jusczyk, P.W. (2001). Episodic memory for musical prosody. Journal of Memory and Language, 45, 526-545.

Papoušek, M. (1992). Early ontogeny of vocal communication in parent-infant interactions. In H. Papoušek, U. Jurgens \& M. Papoušek (Eds.), Nonverbal vocal communication: Comparative and developmental approaches (pp. 230-261). Cambridge: Cambridge University Press.

Peretz, I., Gaudreau, D., \& Bonnel, A.-M. (1998). Exposure effects on music preference and recognition. Memory and Cognition, 26, 884-902.

Plantinga, J., \& Trainor, L.J. (2005). Memory for melody: infants use a relative pitch code. Cognition, 98, 1-11.

Saffran, J.R., Loman, M.M., \& Robertson, R.R.W. (2000). Infant memory for musical experiences. Cognition, 77, B15B23.

Saffran, J.R., Reeck, K., Neibuhr, A., \& Wilson, D. (2005). Changing the tune: the structure of the input affects infants' use of absolute and relative pitch. Developmental Science, $\mathbf{8}$, $1-7$.

Schellenberg, E.G., \& Hallam, S. (2006). Music listening and cognitive abilities in 10- and 11-year-olds: the Blur effect. Annals of the New York Academy of Sciences, 1060, 202-209.

Schellenberg, E.G., Iverson, P., \& McKinnon, M.C. (1999). Name that tune: identifying popular recordings from brief excerpts. Psychonomic Bulletin and Review, 6, 641-646.

Schellenberg, E.G., Nakata, T., Hunter, P.G., \& Tamoto, S. (2007). Exposure to music and cognitive performance: tests of children and adults. Psychology of Music, 35, 5-19.

Schellenberg, E.G., \& Trehub, S.E. (2003). Good pitch memory is widespread. Psychological Science, 14, 262-266.

Shenfield, T., Trehub, S.E., \& Nakata, T. (2003). Maternal singing modulates infant arousal. Psychology of Music, 31, 365-375.

Singh, L., Morgan, J.L., \& Best, C.T. (2002). Infants' listening preferences: baby talk or happy talk? Infancy, 3, 365-394.

Singh, L., Morgan, J.L., \& White, K.S. (2004). Preference and processing: the role of speech affect in early spoken word recognition. Journal of Memory and Language, 51, 173-189.

Thiessen, E.D., Hill, E.A., \& Saffran, J.R. (2005). Infantdirected speech facilitates word segmentation. Infancy, 7, 53-71.

Thompson, W.F., Schellenberg, E.G., \& Husain, G. (2001). Arousal, mood, and the Mozart effect. Psychological Science, 12, 248-251.

Trainor, L.J. (1996). Infant preferences for infant-directed versus noninfant-directed playsongs and lullabies. Infant Behavior and Development, 19, 83-92.

Trainor, L.J., Austin, C.M., \& Desjardins, R.N. (2000). Is infant-directed speech prosody a result of the vocal expression of emotion? Psychological Science, 11, 188-195.

Trainor, L.J., Clark, E.D., Huntley, A., \& Adams, B.A. (1997). The acoustic basis of preferences for infant-directed singing. Infant Behavior and Development, 20, 383-396.

Trainor, L.J., Wu, L., \& Tsang, C.D. (2004). Long-term memory for music: infants remember tempo and timbre. Developmental Science, 7, 289-296.

Trainor, L.J., \& Zacharias, C.A. (1998). Infants prefer higherpitched singing. Infant Behavior and Development, 21, 799805.

Trehub, S.E., Thorpe, L.A., \& Morrongiello, B.A. (1987). Organizational processes in infants' perception of auditory patterns. Child Development, 58, 741-749.

Trehub, S.E., \& Trainor, L.J. (1998). Singing to infants: lullabies and play songs. Advances in Infancy Research, 12, 43-77.

Trehub, S.E., Unyk, A.M., Kamenetsky, S.B., Hill, D.S., Trainor, L.J., Henderson, J.L., \& Saraza, M. (1997). Mothers' and fathers' singing to infants. Developmental Psychology, 33, 500-507.

Unyk, A.M., Trehub, S.E., Trainor, L.J., \& Schellenberg, E.G. (1992). Lullabies and simplicity: a cross-cultural perspective. Psychology of Music, 20, 15-28.

Werker, J.F., \& McLeod, P.J. (1989). Infant preference for both male and female infant-directed talk: a developmental study of attentional and affective responsiveness. Canadian Journal of Psychology, 43, 230-246.

Received: 7 November 2005

Accepted: 15 February 2006 